\title{
The Child and the Family: Interdependence in Developmental Pathways ${ }^{1}$
}

\author{
Kurt Kreppner ${ }^{2}$ \\ Max Planck Institute for Human Development, Berlin, Germany
}

\begin{abstract}
This contribution focuses on the family as the major context for children's development, it includes concepts of the family as an institution for the transmission of meaning on the one hand, and it formulates implications for new theoretical and methodological approaches in the field of family research on the other. The idea of transmission of a society's meaning system via the family is discussed under the perspective that the socialization of children in the family provides a continuous basis for the aggregation of common knowledge over generations. The systems approach is taken as a promising model for dealing with the complex continuity and change issues during development. Data will be presented from two longitudinal studies, in which parent-child communication behavior was analyzed over time during two critical developmental periods, during the first two years after the birth of a second child and during the transition from childhood to adolescence.
\end{abstract}

Key words: family systems; family development; family communication; developmental transitions; transmission of culture.

The idea that families constitute a primary "ecological niche" which provides survival for and socialization of the next generation is very common in everyday life. Within the discipline of developmental psychology, however, this idea has long been neglected and rejected. Only when human ethology revealed the importance of the primary caretaker for the child and the eminent role of the caretakerchild relationship during 60 's and 70 's, the family was rediscovered as a relevant developmental context and attempts were started to link developmental psychology and family research. As a child's survival has been experienced as being dependent on the care of the mother as the primary caregiver, the quality of the relationship between mother and child gained the status of the main aspect of the child's environment. Before the studies in the field of human ethology, a child's environment had been largely depicted as the number of tools available, the housing conditions, or the quality of the neighborhood and the day care centers. Since the late 60 's, the concept of the child as an active participant in the mother-child relationship has considerably changed and widened our view on the role of the family environment. Aside from a functioning mother-child relationship for a healthy development, also fathers began to play an important role for the child's relational context. Today, the child-father relationship represents an important segment of the natural environment in which a child grows up, but this still does not represent the entire relationship network which a child encounters when he or she grows up in a family.

1 Paper based on an invited lecture held at the XXIX Reunião Anual de Psicologia in Campinas, SP, October 28-31, 1999.

2 Correspondence concerning this article should be addressed to Kurt Kreppner. Max Planck Institute for Human Development, DahlemLentzedlee, 94, D-14195 Berlin, Germany. E-mail: kreppner@mpibberlin.mpg.de
In order to represent the entire relational experience which a child encounters when he or she grows up in the natural habitat, the entire relational network of the family appears to be the most realistic context. However, how can the complexity of a network be described which encompasses a multitude of existing relationships in various constellations such as dyadic, triadic, or tetradic interaction patterns? What is an appropriate tool to characterize a family's complex web of relationships including the various ways of the family members to communicate and to establish, maintain, or renegotiate relationships? The following contribution tries to disentangle the role of the family as a relevant context for the developing child by linking individual developmental pathways and family context. In addition, some historical aspects will be elaborated in detail indicating the actual role of the concept of the family in the stream of the historical estimation of development. The emergence of systems theory in physics and biology, and its slow and hesitant application for explaining sequences of behavior patterns of family members as well as its use for conceptualizing the family as a functioning unit in sociological family research and in family therapy, directed also new approaches to think about developmental processes in the family environment. In the retrospective part, the idea of transmission of meaning and culture via the family context into the child is one of the most salient aspects emphasizing the role of the relational environment for personality development. The second part will center around present concepts of family as a context for development, some empirical data will be presented to illustrate the necessity of considering more than static dyadic parent-child relationships when the influence of a complex and dynamic environment on individual developmental pathways is to be assessed. Finally, a number of theoretical as well as methodological issues are presented as a prospect on the future handling of the family and its role as a child's context for development. 


\section{Retrospect}

\section{Transmission of meaning and culture}

The family is often-times defined as the institution for the transmission of genes as well as of culture. It seems that the first aspect - transmission of genes - has been dominant in the discussion about the function of the family during the last years whereas the second aspect has lost importance. Some even believe that the family as an institution aside from the genes has no further relevance for the child's cognitive, emotional, or social development (e.g., Harris, 1995). Although, without doubt, genes are highly relevant for numerous aspects of the developmental process, it should not be forgotten that within the family not only genes are transmitted from one generation to the next, but also meaning and culture. In the following contribution the focus will be on this last aspect. Both some theoretical considerations as well as some empirical evidence for the relevance of the family as context for individual development will be presented.

Since Darwin's $(1859,1871)$ evolution theory, biology and infant psychology have made immense progress in determining human beings as a species governed, aside from individual experience, by endowment defined as a kind of evolutionary imprint in its everyday behavior. The transmission of meaning and culture within the basic intergenerational unit formed by parents and child has been often-times debated under a developmental perspective. Transmission of culture has been claimed to constitute a specific human developmental issue (Cassirer, 1944), and vitalistic perspectives of organism-environment interaction and adaptation were discussed by developmental theoreticians like Mark Baldwin (1894, 1895) or Jean Piaget (1937). Johannes von Uexküll (1909), assisted by the philosopher Ernst Cassirer and the psychologist William Stern (1935), worked on developmental conceptualizations which emphasized the organism's embeddedness in its environment and its "directed development into its specific ecological niche". With his dual approach to describe the interaction between organism and environment, "wirknetz" and "merknetz", that is, network of action and network of perceiving and memorizing, von Uexküll had underlined the organism's relatedness to its environment. Cassirer (1944) argued for a unique human adaptation process, distinguished from adaptations of other species by underscoring the process of transmission of meaning during development. He added a third network, the "symbolic network", to the network of action and of perception, which should characterize the individual's connectedness to the surrounding symbols constituted by language and culture.

Yet, in the human world, we find a new characteristic which appears to be the distinctive mark of human life.The functional circle of man is not only quantitatively enlarged; it has also undergone a qualitative change. Man has, as it were, discovered a new method of adapting himself to his environ- ment. Between the receptor system and the effector system, which are to be found in all animal species, we find in man a third link which we may describe as the symbolic system. This new acquisition transforms the whole of human life. As compared with the other animals man lives not only in a broader reality; he lives, so to speak, in a new dimension of reality. (Cassirer, 1944, p. 24)

Cassirer (1944) tried to add a component to von Uexküll's (1909) adaptation model which represents those essentials that seem necessary to establish a common meaning system and to communicate on a more abstract level beyond immediate needs or emotions. The "new dimension of reality" can be taken, on the one hand, as a new depth in understanding and interpreting our own experiences by being able to refer to interpretations of others. The use of symbols can transform cumbersome pieces of perception into elegant strings of meanings. On the other hand, the use of symbols carries the possibility to participate in experiences of others beyond own perceptions. This may enrich the aggregation of knowledge and lead to a set of categories helpful to interpret the world. Both aspects are fundamental for understanding the role of the family context for a growing child.

When Bertalanffy $(1933,1956)$ had developed his systems view in technology and biology, the idea of a mutual dependency between organism and environment, the notion of adaptation, and the description of dynamics and change processes in development could be further elaborated. Modern systems theory was propelled by mathematicians like Norbert Wiener (1948), who was one of the creators of "cybernetics" and "information theory", concepts by which communication was regarded in terms of transmission and regulation of information between institutions or persons. These ideas were soon adopted to model also transmission processes inside the family, be it for understanding socialization activities, analyzing family malfunctioning, or studying changes in interaction- and communication patterns during different stages of the children's development (Duvall \& Hill, 1945).

The idea of analysing families in terms of their modes to regulate information among members and to convey meaning patterns had been first formulated by Ernest Burgess (1926) - a family researcher who saw families as "superpersonalities" and "growing things". He suggested to use families' communication patterns as main characteristics for distinguishing among types of families and he also underlined an adaptation-oriented and developmental perspective. This idea was extensively applied by Harry Stack Sullivan (1953). He extended the treatment of psychoanalysis to psychotics. Although research with schizophrenics was not successful in terms of communication analysis and the double bind concept, the role of communication in the family, the way of handling information between the family members, became a salient issue in family research. A systemic view opened new perspectives on the understanding of families as an adapting and developing context in which children grow up. Children's sensitiv- 
ity for the quality of relationship, their activity to participate and to pattern the relationship by various modes of communication, their handling of ambiguities in the relationship with the parents moved into the center of attention and interest. For example, when transmission of meaning is interrupted in a parent-child communication, what are the possibilities to regulate or correct this mismatch in a relationship which is basically asymmetric? Is the "sensitivity" of a parent a characteristic which helps to compensate this inequality? Over time, during the development of the child, communication is subject to change depending on children's developmental status and parents' assessments of this status.

For a long time, however, during a period when systemic and action-theoretical concepts were integrated into more and more elaborate concepts of family functioning, developmental issues of children growing up in the family context were not duely considered. Thus, researchers like Kantor and Lehr (1975) with their combination of systemsand action theory and their attempt to emphasize regulation of closeness and distance among family members by their use of space, time, and energy within the family boundaries, classified families only as timeless units. By the same token, change patterns did not come into focus when David Reiss (1981) described and categorized families according to their "paradigm", that is, their specific mode to perceive, interpret, and master critical conditions. Reiss' model did not yet appropriately take into account varying phases in family life according to the children's development but elaborate families' different modes to deal with non-normative transitions, that is, how families reorganize their own functioning to accomplish the task of survival during a state of uncertainty. In contrast to Kantor and Lehr, however Reiss established a model of family functioning which focused on the process of adaptation to maintain the family as a working unit during crises and non-normative transitions. It is a dynamic approach and insofar a model for analyzing normative transitions during development. Both approaches, the model of Kantor and Lehr as well as that of Reiss take families as units which can be characterized by their specific everyday routines, by their rituals, and problem solving strategies in critical situations. As such, each family and its particular way to maintain motivation and meaning among its members can be interpreted as representing a particular "culture", a kind of unit which produces common modes to communicate about the world outside and to evaluate experiences.

\section{The family and its role for the transmission of culture}

The transmission of aggregated knowledge from one generation to the next in the family constitutes a core concept in the cycle of the development of culture. This argument has been already proposed, for example, by Giambattista Vico (1744) during the times of Enlightenment. Here, the concept of family is associated with a relationship-oriented view on human beings and their ability to accumulate knowl- edge over generations and to establish a canon of common values and norms, that is, culture. According to new comparative research, it seems as if the accumulation of culture represents indeed a critical topic when specifics in human development compared to developmental processes in other species are considered. A marked difference, for example, is claimed for the development during the first two years of life in human beings compared to chimpanzees. Carpenter, Nagell, and Tomasello (1998) have drawn the following conclusions from the results of their investigations comparing human infants with chimpnazees:

Certainly, young infants are cultural beings from the beginning in the sense that their development takes place within a particular cultural context that influences many aspects of their cognitive development. But it is only with the emergence of the kinds of social-cognitive abilites that we have investigated here that they become able to tune in to other persons and their cognitive skills directed to outside entities, that is, in a way that fosters acquisition of the conventional use of cultural artefacts such as tools and language - which then serve to mediate their subsequent interactions with their environments in cognitively meaningful ways. This is the essence of the process of enculturation ... The uniqueness of the human adaptation for culture is also brought into stark relief when a comparison is made to our nearest primate relatives. Although there are population differences in the behavior of, for example, different groups of chimpanzees, these primates may be said to have culture in only an extended sense of that term. The reason that they have not created cultures of the human kind is that it appears as though they do not understand their conspecifics as intentional agents like themselves who experience the world in ways similar to the ways in which they themselves do. (pp. 131-132)

Human infants who grow up in a network of relationships very early begin to exchange meanings with their parents and other members of the family and to recognize their intentions. Therefore, the family and its relational network can be taken as an institution in which not only protection of biological functioning and survival is provided, but also maintenance and transmission of cultural values, traditions, and meanings (Bell \& Vogel, 1968; Reiss, 1965; Rodgers, 1973). At the same time, it should be borne in mind that even within the same family patterns of communication and interaction may vary considerably during the course of children's development. Associated with the offspring's changing needs and skills as well as social competencies across the developmental period, the family runs through a series of critical periods which have been described as stages of "family development" (Duvall, 1977), in which family members, both parents and children, have to mutually adapt to new demands and duties. For example, the family's constitution after the birth of a child is a first critical period when the established marital relationship has to be transformed. Coping with these challenges such as establishing a parental aside from the marital relationship between the two partners in the young family is considered to represent the accomplishment of "family tasks", a con- 
cept created by Duvall in analogy with Havighurst's (1953) concept of "developmental tasks", a series of demands a child has to fulfill during development. During critical periods in family development, members negotiate, revalue, reconstruct, and interpret transformations in everyday discussions. Here, the concept of Reiss' model seems to function as a useful template for describing the process of family transition.

When children do not show major deviations from expected behaviors during stable phases of their development, open regulations of rules and conflicts about the child's proper conduct normally remain at a minimum level. However, during periods of developmental change, new needs and demands have to be integrated in the family's lifestyle and canon of rules. During these transition periods, the threat of sanctions for rule transgression and then transformations of these rules becomes a frequent issue. Particularly during the first two years, when the infant develops basic sensorimotoric and social skills and begins to explore the world around him or her, as well as during the transition from childhood to adolescence, when children demand changes in family rules and more autonomy, intergenerational discussions about proper conduct become a relevant topic in family communication.

\section{Research on families: Some specific developmental issues}

\section{Activity of babies, infant-caregiver relationship, and the growing role of the family in early developmental research}

The quality of relationship between infant and mother as well as between infant and father moved to the center of interest during the late sixties and seventies, when the impact of parental influence on the child's course of development was addressed on the one hand, and the infant's own activity in regulating a relationship was observed on the other (Bell, 1968; Escalona, 1973; Rheingold, 1969). Infancy research began to focus on everyday interactions between mothers and children showing the mutuality in early communications. However, a series of studies documented that communication patterns in mother-child dyads do not represent the entire spectrum of infants' early experiences. Quite different communication patterns between parent and infant could be registered, when fathers were observed in interaction with their children during play (Lamb, 1975, 1976; Pedersen, 1975, 1980). Furthermore, mother-child interactions showed variations depending on the fact whether fathers were present in the situation or not. A new interest emerged to investigate not only single parent-child dyads but the entire family encompassing the parent-parent or marital relationship (Pedersen, Anderson, \& Cain, 1980). In his integrated and interdisciplinary approach, Belsky (1981) suggested to apply a holistic strategy for family research. According to the systems analogy he assumed mutual influences between the three relationships in one-child families: the father-child, the mother-child, and the marital relationship.

\section{Impact of parental socialization activities at critical developmental stages during infancy}

In one of our own studies dealing with family development (Kreppner, 1988, 1989, 1991) we focused on the detailed observation of parent-child interaction and communication during the first two years after the birth of a second child. Under a family developmental perspective, it was assumed that parents on the one hand have to reorganize their interaction and communication modes with the second child according to this child's rapid developmental progressions, to integrate this child into the already existing canon of interaction and communication modalities on the other. Thus, particularly during the child's transition to an active social interacting individual, at about 8-9 months, parents are expected to intensify their activities of transmitting cultural rules and norms. During this period, infants reach a new ability which has been described by Trevarthen as "secondary intersubjectivity" (Trevarthen \& Hubley, 1978), the child's intentional stimulation of a parent's reaction by a provocative act, e.g., throwing a cup to the floor and looking not to the cup but instead to possible sudden variations in mother's facial expression.

As our data show, parents do change their communication behavior according to the child's development dramatically around the time when secondary intersubjectivity at $8 / 9$ months is reached. By the same token, verbal instruction is increased when parents realize that the child is beginning to understand language between 12 and 16 months (see figures 1 and 2).

These trends mirror a basic change in socialization practices in the family during a critical developmental period. The trajectories of frequencies representing socialization activities in the family over time illustrate the abrupt onset of parents' regulating activities when the infant has arrived at a new developmental stage of communicative competence. Parents obviously realize the child's increasing tendency to actively test parents' emotional reactions to his or her object manipulations; and they also react to their

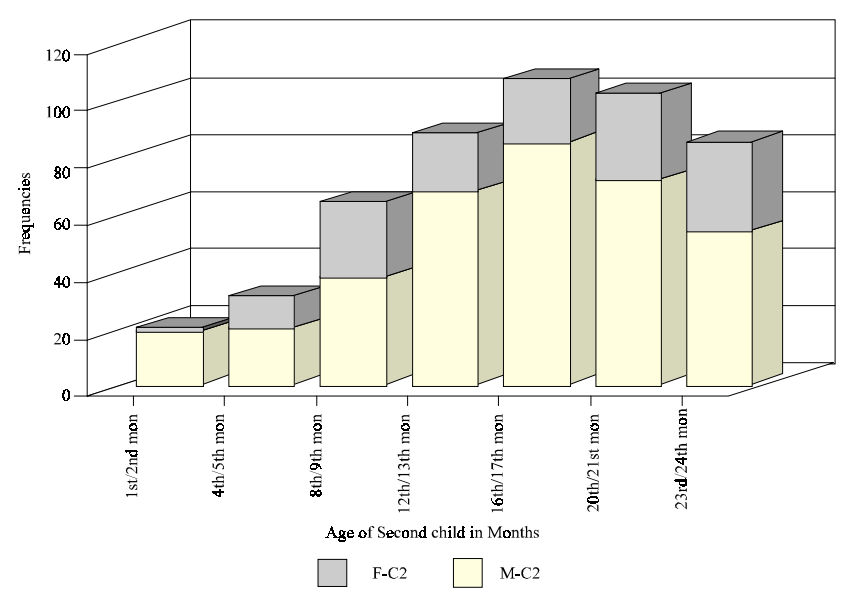

Figure 1. Situation control of mother and father toward the second child. 


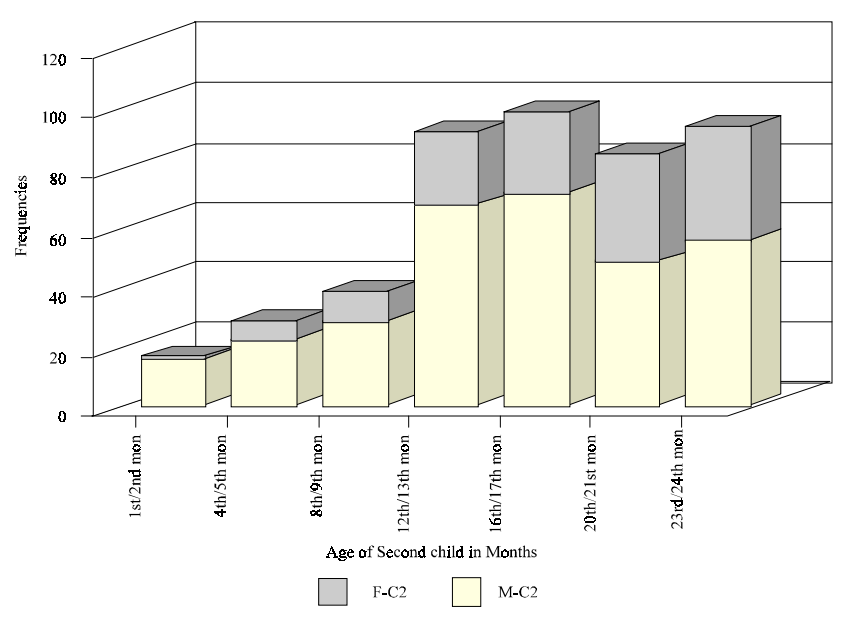

Figure 2. Transmission of rules toward the second child.

offspring's growing ability to understand single words or instructions. When the child is about 16 months old, parental regulating activities reach their peak. After this, control and rule transmission activities slowly decrease towards the end of the second year. Both frequency curves signal major transitions in parental behavior toward the child during the time, when fundamental social-emotional progressions can be observed. Seen from a differential perspective, these changes are good candidates for magnifying family-specific modes to handle transition periods (Kreppner, 1990).

This example has shown general changes in behavior patterns characterizing the parent-child relationship during the time of a family's constitution, a series of other studies have touched upon the young couples difficulties to get along with each other during this period.

\section{The role of marital relationship for a child's development in infancy and in early childhood}

In a longitudinal approach, Cowan and Cowan (1987, 1988, 1992; Cowan, Cowan, Heming, \& Miller, 1991) studied the quality of marital communication patterns and the impact on the child's development. The quality of relationships between the partners during pregnancy was found to be the crucial factor for both parents' and the child's well-being during the transition period from partners to parents. The higher the quality of the marital relationship during pregnancy, the better was the couple's coping with the stress to care for the child during the first months after birth. The role of parents as models for everyday management of exchange between family members, for the production of meaning, and for activities to create a specific quality of relationships within the family is manifest for every child. Numerous studies have shown that marital functioning is important for a child's course of development during infancy and childhood. Development of children's antisocial behavior (Emery 1982, 1988; Emery \& Forehand, 1994), internalization problems and the entire gamut of emotional and cognitive responses to marital conflict (Cummings \& Davies, 1994; Gottman \& Fainsilber-Katz, 1989) have proven the influential power of the quality of marital relationship for children's well being. Moreover, exact observations of differences in mothers' and fathers' parenting styles have created new insights into possible consequences for a child's differential pathway. It is not the difference per se between two parental models which may have a negative influence but the lack of parents' mutual support and acceptance of their different ways to handle the child. Belsky, Crnic, and Gable (1995) demonstrated that a consistent and supportive pattern of coparenting proved to be a relevant aspect for children's coping ability in stressful situations. Particularly the mode of exchange between parents and children about emotions represents another aspect that emerged as a new access for understanding differences in the development of children (Gottman, Fainsilber-Katz, \& Hooven, 1996).

A meta-analysis conducted by Erel and Burman (1995) also revealed direct influences between the quality of the marital relationship and the quality of the child's relationship with the parents. This analysis of quite a number of different studies disclosed wide support for the spillover hypothesis, that is, that transfer exists between one sub-system in the family (e.g., parent-parent dyad) to the other (e.g., parent-child dyad). However, when concrete moderators of this transfer were debated, no clear results could be found. Although some indicators could be isolated pointing to links between single negative parental communication characteristics, such as angry and withdrawing fathers or overcritical and intruding mothers, and children's internalizing or externalizing behavior (Fainsilber-Katz \& Gottman, 1993; Fainsilber-Katz \& Kahen, 1993), only very few studies have tried to find out more details about typical courses of marital communication patterns leading to either harmonic or disharmonic endings (Gottman, 1994) and, at the same time, influencing the children's developmental pathways.

\section{Transition to adolescence: Family communication patterns}

\section{Communication changes within the family}

During transition to adolescence, the child has to develop a new sense of self, the skill to affirm his/her own position against resistance of the parents, and the competence to initiate new relationships and to reorganize existing ones. Parents and child are expected to change their communication patterns over time (Hill, 1983, 1987), particularly when conflicts between the generations are to be regulated. Broderick and Smith (1979) gave an excellent example for such regulations and, in addition, for the course of changes in family rules and negotiations techniques during this adaptation process, when parents, in the end, give way to their child's growing protest against household chores like cleaning up the room. In general, discussions in parent-child dyads may show an increment in those communication patterns which indicate a more adult-like exchange patterns during the transition period. 


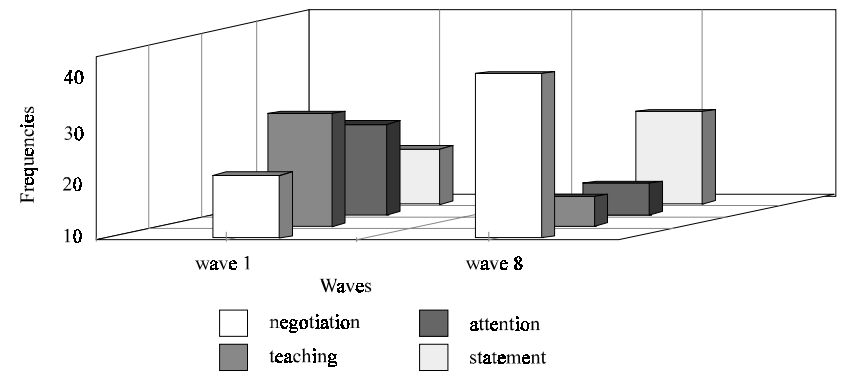

Figure 3. Communication style over time: Mothers with adolescents.

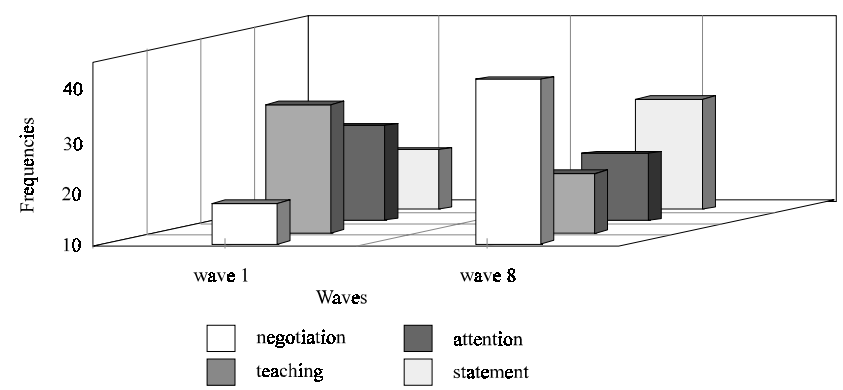

Figure 4. Communication style over time: Fathers with adolescents.

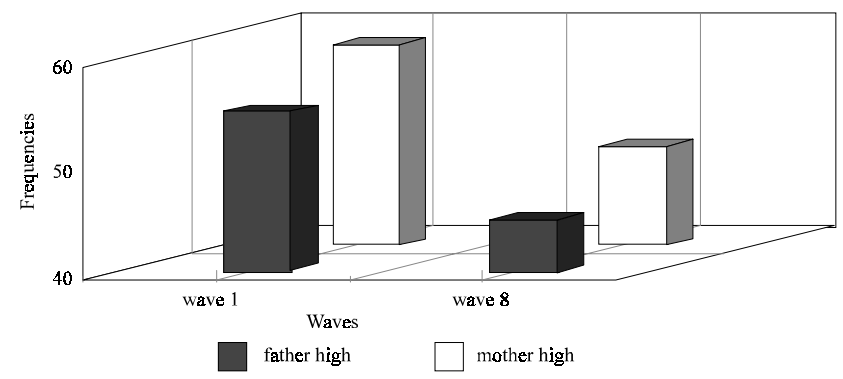

Figure 5. High closeness over time: Parents with adolescents.

These time-specific changes of communication patterns were found in our own study which dealt with families and their adolescent children (Kreppner, 1995, 1996; Kreppner \& Ullrich, 1998). Communication behaviors measured in dyadic situations (see Kreppner \& Ullrich, 1996, for details), between mother and adolescent as well as between father and adolescent exhibited similar trends over time, when children were about 11,5 years old at the beginning of the study and about 15 years at the end of our data collection. Frequencies for parental communication styles like "teaching" or "giving attention" went down during the three and a half year period, whereas frequencies for behaviors like "negotiation" or "exchange of statements", that is, affirmation of one's own position, increased (see figures 3 and 4).

As to nonverbal communication changes in the parentchild dyad, the degree of high closeneness shown by both parents during the first year of our data collection (when the children were about 11,6 years old) decreased considerably when the children had reached the age of fifteen years (see figure 5).

Astonishing enough, there were also changes over time in the mother-father exchanges without the child present.

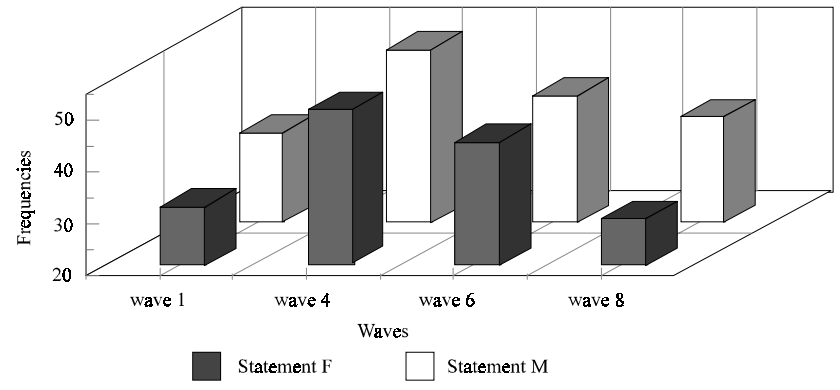

Figure 6. Parental communication over time: Using statements in motherfather dyad.

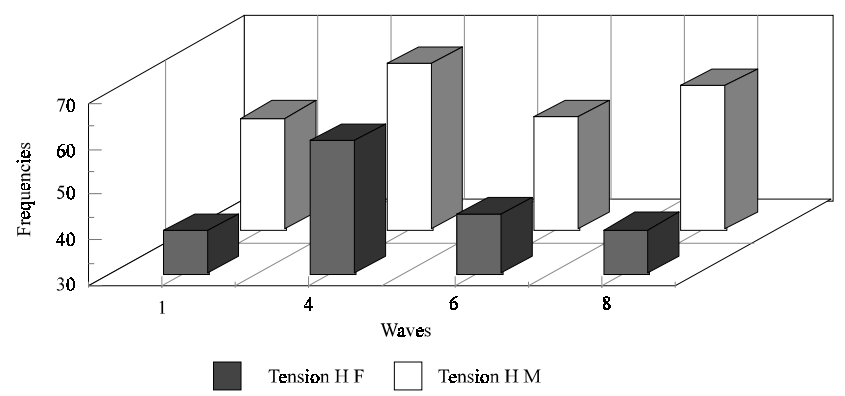

Figure 7. Parental communication over time: Tension high in mother-father dyad.

For example, the exchange of statements in discussion reached a peak when the child was 13 years old (see figure 6 ), but also the degree of tension between the parents was highest in their discussions at that time (see figure 7).

\section{Family development: Differences in communication patterns}

In adolescence research, differences in family conversation and their impact on developmental pathways were studied by Stuart Hauser (Hauser, Powers, \& Noam, 1991) and coworkers as well as by Grotevant and Cooper $(1983,1985)$. Elements of conversations in the family such as challenging statements, supporting or discouraging remarks characterize two different patterns, enabling and disabling communication patterns, which are believed to be highly relevant for the development of different selves. Differences in the families' ways to produce meaning may provide extremely valuable information about the social competencies children can develop in various family and peer contexts (Youniss, 1983, 1989; Youniss \& Smollar, 1985).

In our longitudinal observational study with families and their adolescent children, we focused not only on general change trends but also on adolescents' experiences of differential communication patterns during the transition period. Adolescents' subjective assessments of the quality of relationship with their parents (see Spiel, Kreppner, \& von Eye, 1995, for details) were used as a grouping criterion for analyzing details of diverging parent-adolescent communication behaviors over time. Applying cluster analysis (Ward, 1963), we could identify three clusters which were labelled as groups containing adolescents who have a "se- 


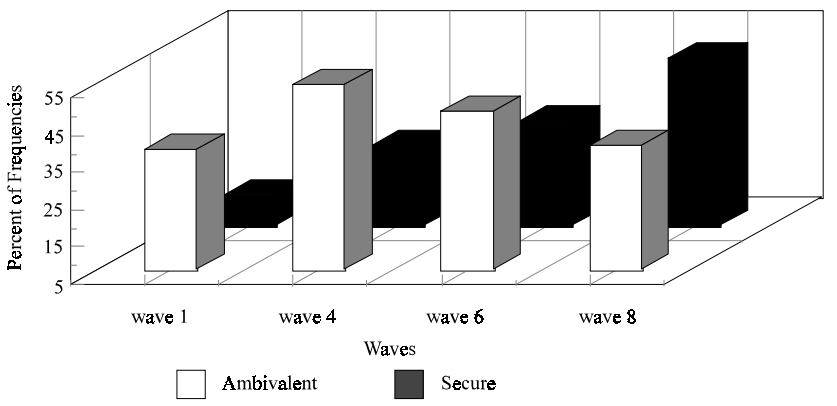

Figure 8. Communication style over time. Statements: Fathers to adolescents.

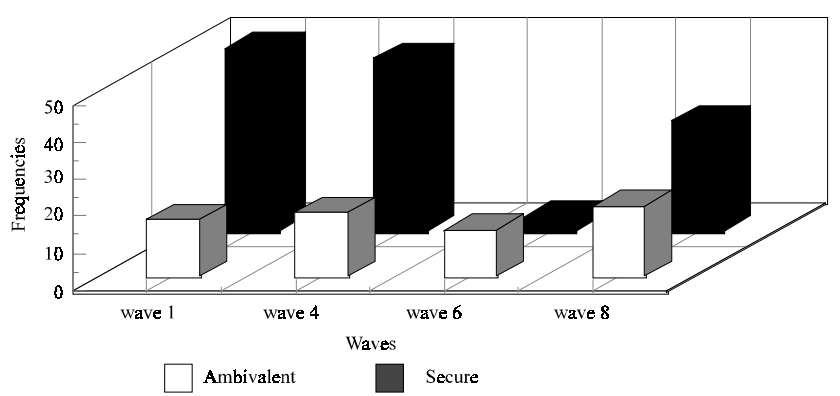

Figure 9. Communication style over time. Egalitarian: Fathers to adolescents.

cure", "habitual", or "ambivalent" relationship with their parents (see Kreppner, 1996, for details).

The most striking result for different communication behaviors within the family was found for those two groups in which adolescents had given consistently diverging assessments about the quality of the relationship with the parents as being either "secure" or "ambivalent". For the "secure" adolescents, paternal communication behavior varied considerably over time with regard to specific aspects like the use of statements in discussions with the child, that is, exchange of different opinions without a common solution, or of an exchange mode embedded in an egalitarian context. For the "ambivalent" adolescents, fathers in their discussion behaviors did not show such variations during the transition period (see figures 8 and 9).

Another marked difference between the two groups (secure and ambivalent adolescents) is indicated by the emotional climate during the discussions, between parents and children as well as between the two parents. The category "high closeness" describes how discussion partners produce the climate which either fosters or impedes the flux of verbal exchanges. The consistent differences in frequency distributions between the two groups of families in the motheradolescent, father-adolescent, and mother-father dyad impressively show the dissimilar worlds of communication in which adolescents may grow up (see figures 10, 11, and 12).

In sum, parent-adolescent relationships do undergo some changes during the passage from childhood to adulthood and it could be shown in a few examples that families run through this transition period with different adaptive skills. Families do not only show divergent patterns of communi-

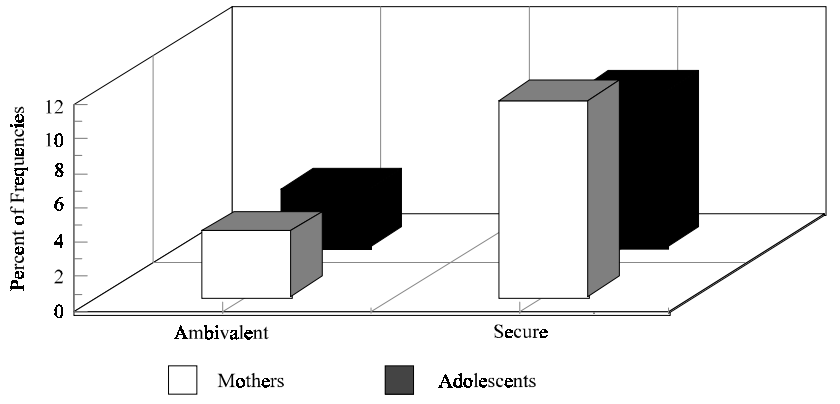

Figure 10. Mutual nonverbal communication. High closeness: Mothers and adolescents.

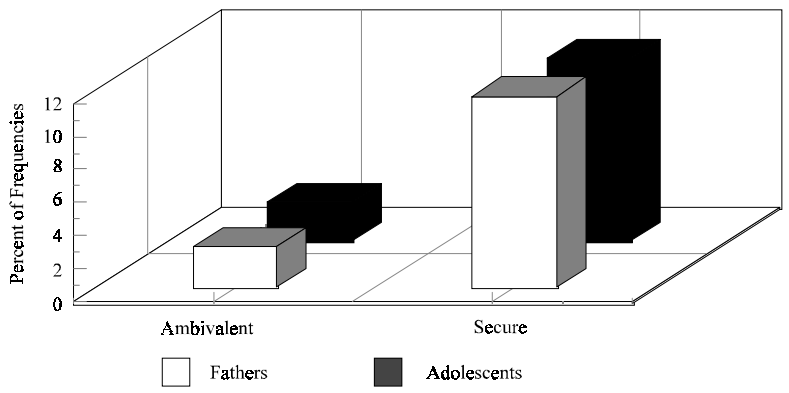

Figure 11. Mutual nonverbal communication. High closeness: Fathers and adolescents.

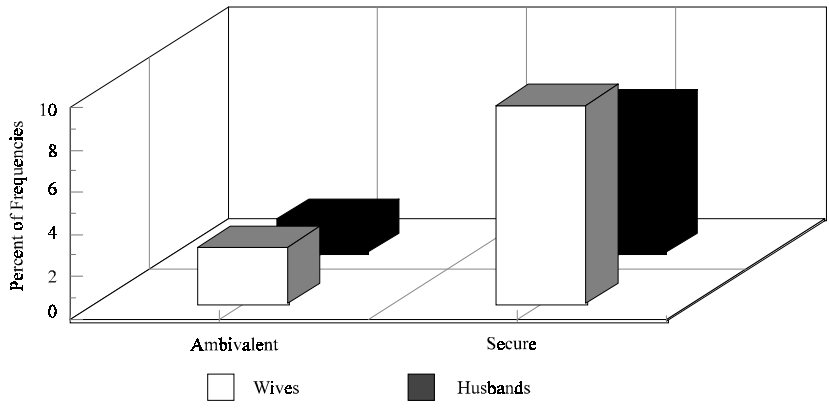

Figure 12. Mutual nonverbal communication. High closeness: Wives and husbands.

cation when dealing with transition problems but also differ in their flexibility to adapt to their children's changing demands for more autonomy and adult communication. Moreover, they also produce different qualities of emotional closeness in the family when discussing mundane issues in their everyday exchanges.

\section{The impact of the quality of marital relationship for adolescent development}

In a longitudinal study, Feldman, Fisher, and Seitel (1997) have shown that marital satisfaction during the child's adolescence was an important predictor of subsequent emotional and physical health of children six years later. Moreover, a growing corpus of data is now indicating that the quality of relationship between both parents essentially influences the children's development (Davies \& Cummings, 1998; Harold $\&$ Conger, 1997). From this perspective, it seems worth- 
while to study a family's microcosm in its many details at specific transition periods in the family life cycle. As conflictual parent-parent relationships have been shown to produce spill-over effects for parent-child relationships, that is, tensions in the marital relationship produce a malfunctioning parent-child relationship, children's and adolescents' behaviors after divorce cannot solely be attributed to the act of divorce alone. Rather, impairment in development evolves as a product of children's experiences in their families long before parents finally separate, as these children grow up in the context of a deteriorating parent-parent relationship. Thus, behavior problems, maladjustments, poor social skills, and - particularly during adolescence - disengagement from the family is more prevalent in children from divorced than from nondivorced families (Block, Block, \& Gjerde, 1986; Cherlin, Furstenberg, Chase-Landsdale, Kiernana, Robins, Morrison, \& Teitler, 1991; Hetherington, 1979). Moreover, academic achievement and antisocial behavior appear also to be strongly influenced by family status (Zill, 1994).

\section{Prospect: Conclusions and a look into the future}

\section{A perspective on family communication emphasizing its function for the child's mastering of developmental transitions}

Families are not just well-established groups of individuals with a kind of robust and never-changing set of intragroup relationships. On the contrary, families are more or less fragile constructs which permanently have to adapt to challenges generated by non-normative events as well as by normative individual developmental processes. Families do differ considerably with regard to their ability to adapt to developmental demands of their children and to their openness for new solutions for continuing family life. Families show a variety of ways in which they pay attention to each others' needs, in which they react to developmental changes and regulate the single members' space to live their own interests. Differences in communication behavior are salient not only in parent-child, but also in parent-parent dyads. The different modalities by which parents and children communicate with one another have long been considered as salient mediators for rules, regulations, and values inside the family. Moreover, as knowledge grew about intricate details of the relatedness between mother-child and father-child communication (e.g. Clarke-Stewart, 1988), more concepts emerged carrying a sophisticated view of a family's impact on a child's well-being and the parents' own development (Silverberg, 1996).

Future longitudinal studies have to find out which aspects of verbal and nonverbal communication patterns seem to be prototypical for the establishment of secure relationships within the family, which interaction behavior is supporting or impeding a child's development in his or her family. We still do not know much about the essentials of the quality of communication patterns within the family at different periods of the child's development. We did accu- mulate so far some hints but no exact details about the kind of communication context that may contribute directly to the child's feeling of well being or ambivalence, to the possibility or impossibility to regulate emotions within a relationship and to the development of social competence or incompetence in the child. The eminent role of the fathers, evident also in some of our own results, is still largely unknown in its concrete impact within the complex network of family interactions. Particularly time-specific effects of communication exchanges within the family, the role of the marital communication, and the flexibility of exchange modes should be studied more intensely. Finally, critical transition phases in adult development and their possible impact both on parent-parent communication and family climate represent splendid candidates for those time windows in which future research could be intensified. Having aggregated now some general information about communication and interaction practices within families, we need more detailed long-term and single-case information.

Future perspectives on family research should concentrate on overcoming the still existing huge differences in theoretical frameworks used to design studies on developmental processes. As two different worlds have to merge, the world of individualistic and psychological thinking about child development and the world of interactionistic and sociological thinking about the family as an institution are still too far apart to allow easy exchanges. Lacking flexibility of creating variables which would fit into both frameworks, wide distance and continuing misunderstandings between the two camps still remain. Although some progress may have been made, research designs still seem to be committed to quite different worldviews: Mechanistic stand against organismic concepts. Another obstacle to gain quick access to relevant knowledge is the often-mentioned dissimilarity of socialization practices in different societies and cultures. Of course, these differences should not be neglected or simplified. However, under a relationship-quality perspective, culture-specific patterns of child socialization might be linked to more overarching aspects of necessary adaptation and intergenerational continuation. Patterns of parent-child relationships may differ among cultures, but they all have to meet a number of universal prerequisites to secure the child's basic needs and to socialize the new member into the common canon of value and norms which links the present with the next generation.

\section{A tentative look into the future of family research}

A general and overarching perspective should be emphasized, when future research on family as developing systems is regarded: As a tentative guideline for future research in the area of family and family development, seven points are listed below:

1. Family research should strongly focus on the analysis of relationships, their quality, history, flexiblity and resiliency under stress. Nonrelational aspects, such as single members' temperaments, traits, or pathologies 
should be linked to the various aspects of a family's relationship quality.

2. In family studies, both verbal and nonverbal exchanges in a relationship should be analyzed. Exchange about objects, persons, and situation is only one aspect in the communication between two people. The other aspect encompasses the regulation of the relationship between the two communicating people, its symmetry or asymmetry and, linked to it, the range of information that can be exchanged. Although contents and relationship are negotiated in both verbal and nonverbal modes, nonverbal information is crucial for gaining a comprehensive interpretation of meanings conveyed in verbal communication.

3. All relationships in a family have to be regarded when research about families is conducted. By the same token, also all constellations such as dyads, triads, tetrads and so forth must be considered when relationship patterns within families are investigated. As studies comparing dyadic and triadic interactions have shown, dynamics between the same persons may vary considerably in different constellations.

4. Family research should always keep as a working hypothesis that families are institutions in which, among other functions, the production, maintenance, and transmission of meaning and culture are central. Thus, the production of meaning, the quality of flow of meaning between family members could be a favorite topic.

5. When analyzing communication and interaction within the family we should try to create more variables depicting relationship characteristics on a molar level. Micro-level analyses, useful for specific questions and elaborations, very often seem to lead to elementaristic and reductionistic interpretations of complex and timespecific behavior patterns. Research could take more effort to look after something like a depth-dimension in human communication. ${ }^{3}$

6. As a research strategy, family research could concentrate on specific phases where transitions have to be mastered. During a transition phase, the families' modes to handle different interests and divergent problem-solving strategies can be observed in full detail. A focus on the family's attempts to keep an old or to look for a new state of equilibrium could help better characterize a family's mode to negotiate extant relationships in everyday communication.

7. New methodological approaches are needed. The follow-up of families through several stages of their life-

3 This is a dimension which Kurt Lewin (1927) had labelled as "conditional-genetic" dimension in contrast to the "phenomenal" or surface dimension. By this conditional-genetic dimension, he meant the dimension that unveils the conditions that create concrete behavior patterns which are then visible at the surface in different forms. Examples of such molar communication patterns could be varibles such as "capacity of transmitting social quality", "model for guidance in a well-organized relationship", "potential for correcting misunderstandings", or "creation of meaning during exchange". time needs to take into account the specific modalities of communication in order to segregate relevant from irrelevant aspects and events. Both larger representative samples and more detailed longitudinal case studies which can be located in the larger samples are needed.

\section{A final thought}

A look forward seems to be rather meaningless if there is no comparison with a look in to the other direction. Therefore, at the end of this contribution, two general perspectives will be addressed which were formulated by two philosophers who were already mentioned to at the beginning. Both have tried to emphasize the specific role of communication with others and the importance of culture as essential aspects for understanding human nature and behavior. Both are well known for their critique of an all too mentalistic or cognitivistic approach in the human sciences.

Giambattista Vico was a philosopher who made every effort to keep alive a tradition which seemed to be lost after Descartes and during the times of Enlightenment and Rationalism. In his book The new science (1744), Vico argued against the extreme reductionism in Descartes' "cogito" as the only sign of truth for human existence. According to Vico, Descartes, by introducing his 'method of doubt' was neglecting all common sense experiences which constitute what is called 'human nature', that is, historical traditions, jurisprudence, sciences of language, rhetorics, the arts, and political pragmatics, in short all topics in humanities which are based on human communication. The discursive production and maintenance of meaning, our main focus in family research, leads us perhaps far back in the history of epistemology. It carries us into an era of philosophical thinking which was, under a today's perspective, fundamentally different from our view on reality and logic. We enter the period before Descartes, the time of early Humanism and Renaissance, when law and medical sciences were the prototypes for finding general solutions in the sciences.

Ernst Cassirer, in his famous 'An essay on man' (1944) has put this perspective in a more general statement about the non-empirical and reductionistic character of the rational concept of human nature:

The great thinkers who have defined man as an 'animal rationale' were not empiricists, nor did they ever intend to give an empirical account of human nature. By this definition they were expressing rather a fundamental moral imperative. Reason is a very inadequate term with which to comprehend the forms of man's cultural life in all their richness and varieties. (pp. 25-16)

If we state that the family is the institution in which meaning is produced for the next generation, in which culture is transmitted, where, in addition, the skills for establishing and maintaining relationships and the arts of communication are conveyed, research on families should indeed focus more on these particular issues in more detail. 
Some current longitudinal research conducted, for example, at Harvard and in Minneapolis, does show promising tendencies. Stuart Hauser (1999) published just a first attempt of his single case continuation on protective factors which might open a window for new perspectives on relevant factors of family life for individual developmental progress. The Minneapolis longitudinal study which follows children and their attachment status in infancy over adolescence into their establishments of romantic relationships during early adulthood represents another promising attempt to gain information about the impact of relationship quality on the course of individual development (Collins, 1998). Moreover, family narratives have gained new interest in developmental psychology during the last years. Parents' ways to talk about their own history, their families of origin, is an important part of the context, in which a child grows up. In a recent publication, Fiese, Sameroff, Grotevant, Wamboldt, Dickstein, and Fravel (1999) proposed dimensions like coherence, interaction, and relationship beliefs as relevant aspects for distinguishing families' communication contexts.

Even after Descartes and his reductionistic cognitive solution for the explanation of human existence, we hopefully still find rich thinking alive in science for a more advanced and open vision of the human beings in their interrelatedness with an intergenerational and cultural context.

\section{References}

Baldwin, J. M. (1894). Imitation: A chapter in the natural history of consciousness. Mind, 3, 26-55.

Baldwin, J. M. (1895). Mental development in the child and the race. New York: MacMillan.

Bell, R. Q. (1968). A reinterpretation of the direction of effects in studies of socialization. Psychological Review, 75, 81-95.

Bell, N. W., \& Vogel, E. F. (Eds.). (1968). A modern introduction to the family. New York: The Free Press.

Belsky, J. (1981). Early human experience: A family perspective. Development Psychology, 17, 3-23.

Belsky, J., Crnic, K., \& Gable, S. (1995). The determinants of coparenting in families with toddler boys: Spousal differences and daily hassles. Child Development, 66, 629-642.

Bertalanffy, L.v. (1933). Modern theories of development: An introduction to theoretical biology. London: Oxford University Press.

Bertalanffy, L.v. (1956). General system theory. In L. Bertalanffy \& A. Rapoport (Eds.), General systems. Yearbook of the Society for the Advancement of General Systems Theory, 1, 1-10.

Block, J. H., Block, J., \& Gjerde, P. F. (1986). The personality of children prior to divorce: A prospective study. Child Development, 57, 827-840.

Broderick, C., \& Smith, J. (1979). The general systems approach to the family. In W. Burr, R. Hill, F. Nye, \& I. Reiss (Eds.), Contemporary theories about the family (Vol 2, pp. 112-129). New York: The Free Press.

Burgess, E. (1926). The family as a unity of interacting personalities. Family, 7, 3-9.
Carpenter, M., Nagell, K., \& Tomasello, M. (1998). Social cognition, joint attention, and communicative competence from 9 to 15 months of age. Monographs of the Society for Research in Child Development, 63 (4, Serial No. 255).

Cassirer, E. (1944). An essay on man. An introduction to a philosophy of human culture. New Haven: Yale University Press.

Cherlin, A. J., Furstenberg, Jr. F. F., Chase-Lansdale, P. L., Kiernana, K. E., Robins, P. K., Morrison, D. R., \& Teitler, J. O. (1991). Longitudinal studies of effects of divorce on children in Great Britain and the United States. Science, 252, 1386-1389.

Clarke-Stewart, K. A. (1988). Parents' effects on children's development: A decade of progress? Journal of Applied Developmental Psychology, 9, 41-84.

Collins, W. A. (1998, February). Late adolescent competence in developmental perspective: Issues from a 19-year study. Paper presented at the Seventh Biennial Meeting of the Society for Research on Adolescence, San Diego, California.

Cowan, C. P., \& Cowan, P. A. (1987). Men's involvement in parenthood: Identifying the antecedents and understanding the barriers. In P. W. Berman \& F. A. Pedersen (Eds.), Men's transition to parenthood (pp. 145-174). Hillsdale, NJ: Erlbaum.

Cowan, P. A., \& Cowan, C. P. (1988). Changes in marriage during the transition to parenthood. In G. Y. Michaels \& W. A. Goldberg (Eds.), The transition to parenthood: Current theory and research (pp. 114-154). Cambridge, UK: Cambridge University Press.

Cowan, C. P., \& Cowan, P. A. (1992). When partners become parents: The big life change for couples. New York: Basic Books.

Cowan, C. P., Cowan, P. A., Heming, G., \& Miller, N. B. (1991). Becoming a family: Marriage, parenting, and child development. In P. A. Cowan \& M. Hetherington (Eds.), Family transitions (pp. 79-109). Hillsdale, NJ: Erlbaum.

Cummings, E. M., \& Davies, P. (1994). Children and marital conflict: The impact of family dispute and resolution. New York: Guilford.

Darwin, C. (1859). On the origin of species. London: John Murray.

Darwin, C. (1871). Descent of man. London: John Murray.

Davies, P. T., \& Cummings, E. M. (1998). Exploring children's security as a mediator of the link between marital relations and child adjustment. Child Development, 69, 124-139.

Duvall, E. (1977). Marriage and family development. New York: Lippincott.

Duvall, E., \& Hill, R. (1945). When you marry. New York: Association Press.

Emery, R. E. (1982). Interparental conflict and the children of discord and divorce. Psychological Bulletin, 92, 310-330.

Emery, R. E. (1988). (Ed.). Marriage, divorce, and children's adjustment. Newbury Park, CA: Sage.

Emery, R. E., \& Forehand, R. (1994). Parental divorce and children's well-being: A focus on resilience. In R. J. Haggerty, L. R. Sherrod, N. Garmezy, \& M. Rutter (Eds.), Stress, risk, and resilience in children and adolescents (pp. 64-99). Cambridge, England: Cambridge University Press.

Erel, O., \& Burman, B. (1995). Interrelatedness of marital and parent-child relations: A meta-analytic review. Psychological Bulletin, 118, 108-132. 
Escalona, S. K. (1973). Basic modes of social interaction: Their emergence and patterning during the first two years of life. Merrill Palmer Quarterly, 19, 205-232.

Fainsilber-Katz, L., \& Gottman, J. M. (1993). Patterns of marital conflict predict children's internalizing and externalizing behaviors. Developmental Psychology, 29, 940-950.

Fainsilber-Katz, L., \& Kahen, V. (1993, March). Marital interaction patterns and children's externalizing and internalizing behaviors: The search for mechanisms. Paper presented at the Biennial Meetings of the Society for Research in Child Development, New Orleans, LA.

Feldman, S. S., Fisher, L., \& Seitel, L. (1997). The effect of parents' marital satisfaction on young adults' adaptation: A longitudinal study. Journal of Research on Adolescence, 7, 55-80.

Fiese, B. H., Sameroff, A. J., Grotevant, H. D., Wamboldt, F. S., Dickstein, S., \& Fravel, D. L. (1999). The stories that families tell: Narrative coherence, narrative interaction, and relationship beliefs. Monographs of the Society for Research in Child Development, 64 (2, Serial No. 257).

Gottman, J. M. (1994). What predicts divorce? Hillsdale, NJ: Erlbaum.

Gottman, J. M., \& Fainsilber-Katz, L. (1989). Effect of marital discord on young children's peer interaction and health. Developmental Psychology, 25, 373-381.

Gottman, J. M., Fainsilber-Katz, L., \& Hooven, C. (1996). Metaemotion: How families communicate emotionally. Mahwah, NJ: Erlbaum.

Grotevant, H. D., \& Cooper, C. R. (Series and Vol. Eds.). (1983). New directions for child development: Vol. 22. Adolescent development in the family. San Francisco: Jossey Bass.

Grotevant, H. D., \& Cooper, C. R. (1985). Patterns of interaction in family relationships and the development of identity exploration in adolescence. Child Development, 56, 415-428.

Hauser, S. T. (1999). Understanding resilient outcomes: Adolescent lives across time and generations. Journal of Research on Adolescence, 9, 1-24.

Hauser, S. T., Powers, S. I., \& Noam, G. G. (1991). Adolescents and their families. New York: The Free Press.

Harold, G. T., \& Conger, R. D. (1997). Marital conflict and adolescent distress: The role of adolescent awareness. Child Development, 68, 333-350.

Harris, J. R. (1995). Where is the child's environment? A group socialization theory of development. Psychological Review, $102,458-489$.

Havighurst, R. J. (1953). Human development and education. New York: David McKay.

Hetherington, E. M. (1979). Divorce: A child's perspective. American Psychologist, 34, 851-858.

Hill, J. P. (1983). Early adolescence: A research agenda. Journal of Early Adolescence, 3, 1-21.

Hill, J. P. (1987). Research on adolescents and their families: Past and prospect. In W. Damon (Series and Vol. Ed.), New directions for child development: Vol 37. Adolescent health and social behavior (pp.13-32). San Francisco: Jossey Bass.

Kantor, D., \& Lehr, W. (1975). Inside the family. San Francisco: Jossey Bass.
Kreppner, K. (1988). Changes in parent-child relationships with the birth of the second child. Marriage and Family Review, $12,157-181$.

Kreppner, K. (1989). Linking infant development-in-context research to the investigation of life-span family development. In K. Kreppner \& R. M. Lerner (Eds.), Family systems and life-span development (pp. 33-64). Hillsdale, NJ: Erlbaum.

Kreppner, K. (1990, October). Differences in parents' cooperation patterns after the arrival of a second child. Paper presented at the International Conference BABY XXI, Lisbon, Portugal.

Kreppner, K. (1991). Observation and the longitudinal approach in infancy research. In M. Lamb \& H. Keller (Eds.), Infant development: Perspectives from German-speaking countries (pp. 151-178). Hillsdale, NJ: Erlbaum.

Kreppner, K. (1995). Differential experiences within the family during adolescence: Consistencies of relationship assessments and concrete communication behaviors over time. In J. J. Hox, B. F. van der Meulen, J. M. A. M. Janssens, J. J. F. ter Laak, \& L. W. C. Tavecchio (Eds.), Advances in family research (pp. 103-122). Amsterdam: Thesis Publishers.

Kreppner, K. (1996). Kommunikationsverhalten zwischen Eltern und ihren jugendlichen Kindern und der Zusammenhang mit Indikatoren des Selbstwertgefühls [Communication behavior in the family and the development of self-esteem during adolescence]. Praxis der Kinderpsychologie und Kinderpsychiatrie, 45, 130-147.

Kreppner, K., \& Ullrich, M. (1996). Familien-Codier-System. Beschreibung eines Codiersystems zur Beurteilung von Kommunikationsverhalten in Familiendyaden [Family Coding System. Description of a coding system for the assessment of communication behavior in family dyads]. Materialien aus der Bildungsforschung, 57, Berlin: MaxPlanck-Institut für Bildungsforschung.

Kreppner, K., \& Ullrich, M. (1998). Talk to mom and dad, and listen to what is in between. In M. Hofer, P. Noack \& J. Youniss (Eds.), Verbal interaction and development in families with adolescents (pp. 83-108). Greenwich, CT: Ablex.

Lamb, M. (1975). Father: Forgotten contributors to child development. Human Development, 18, 245-266.

Lamb, M. E. (1976). The role of the father in child development. New York: Wiley.

Lewin, K. (1927). Gesetz und Experiment in der Psychologie [Law and experiment in psychology]. Symposium, 1, 375-421.

Pedersen, F. A. (1975, August). Mother, father, and infant as an interaction system. Paper presented at the Annual Convention of the American Psychological Association, Chicago.

Pedersen, F. A. (1980). The father-infant relationship. New York: Praeger.

Pedersen, F. A., Anderson, B. J., \& Cain, R. L. (1980). Parentinfant and husband-wife interactions observed at age five months. In F. A. Pedersen (Ed.), The father-infant relationship (pp. 71-86). New York: Praeger.

Piaget, J. (1937). La construction du réel chez l'enfant [The construction of reality in the child]. Neuchatel: Delachaux et Niestlé.

Reiss, D. (1981). The family's construction of reality. Cambridge, Mass.: Harvard University Press. 
Reiss, I. L. (1965). The universality of the family: A conceptual analysis. Journal of Marriage and the Family, 27, 343-353.

Rheingold, H. L. (1969). The social and socializing infant. In D. A. Goslin (Ed.), Handbook of socialization theory and research (pp. 779-790). Chicago: Rand McNally.

Rodgers, R. (1973). Family interaction and transaction. The developmental approach. Englewood Cliffs, NJ: Prentice Hall.

Silverberg, S. B. (1996). Parents' well-being at their children's transition to adolescence. In C. D. Ryff \& M. M. Seltzer (Eds.), The parental experience in midlife (pp. 215-254). Chicago: University of Chicago Press.

Spiel, C., Kreppner, K., \& von Eye, A. (1995). Die FamilienBeziehungs-Skalen, FBS: Bericht über die Entwicklung eines Screening Instruments zur Erfassung von Beziehung Jugendlicher zu ihren Eltern [Family Relationship Scales, FBS. Report on the development of a screening instrument for the assessment of adolescents' relationship with their parents]. Diagnostica, 41, 322-333.

Stern, W. (1935). Allgemeine Psychologie auf personalistischer Grundlage [General psychology on a personalistic basis]. Den Haag: Martinus Nijhoff.

Sullivan, H. S. (1953). The interpersonal theory of psychiatry. New York: Norton.

Trevarthen, C., \& Hubley, P. (1978). Secondary intersubjectivity: Confidence, confinding and acts of meaning in the first year.
In A. Lock (Ed.), Action, gesture and symbol (pp. 183-229). London: Academic Press.

Uexküll, von, J. J. (1909). Umwelt und Innenwelt der Tiere [Environment and inner world of animals]. Berlin: Springer.

Vico, G. (1744). Die neue Wissenschaft über die gemeinschaftliche Natur der Völker [The new science]. Hamburg: Rowohlt.

Ward, J. H. (1963). Hierarchical grouping to optimize an objective function. Journal of the American Statistical Association, 58, 236-244.

Wiener, N. (1948). Cybernetics. New York: Wiley.

Youniss, J. (1983). Social construction of adolescence by adolescents and parents. In H. D. Grotevant (Series Ed.) \& C. R. Cooper (Vol. Ed.), New directions for child development: Vol 22. Adolescent development in the family (pp. 93-110). San Francisco: Jossey Bass.

Youniss, J. (1989). Further thoughts on social construction in families. Journal of Family Psychology, 3, 61-63.

Youniss, J., \& Smollar, J. (1985). Adolescent relations with mothers, fathers, and friends. Chicago: University of Chicago Press.

Zill, N. (1994). Understanding why children in stepfamilies have more learning and behavior problems than children in nuclear families. In A. Booth \& J. Dunn (Eds.), Stepfamilies. Who benefits? Who does not? (pp. 97-106). Hillsdale, NJ: Erlbaum. 